\title{
Ritornelos da expressão audiovisual nas redes midiáticas: métodos ecléticos do videomashup
}

\author{
Rodrigo Fonseca e Rodrigues
}

Resumo: Às experimentações concretistas do século XX sucederam-se, nas últimas décadas, outras expressões que passaram a explorar os próprios repertórios culturais midiáticos e respectivos regimes de experiência como materiais de invenção, viabilizadas pelos dispositivos informáticos de audiovisual e pelas redes digitais. Este artigo aborda, a título de corpus empírico, os videomashups do projeto Eclectic Method como pastiches de um cariz concretista e que se valem de sonoridades, imagens e discursos recorrentes na cultura das mídias e na internet. Os conceitos filosóficos do "ritornelo" e de "corte" desenvolvidos por Deleuze e Guattari (1997a) serão revisitados para se problematizarem o groove e o cut'n'paste como métodos a partir dos quais os "vjays de mixtape" capturam e reagenciam materiais "audiologo-visuais" das redes midiáticas. Ao injetarem paradoxos na experiência saturada, estes "artistas-curadores" provocam experimentações sobre a escuta, a visualidade e a imaginação.

Palavras-chave: expressões audiovisuais; redes midiáticas; videomashup; ritornelo.

Abstract: Refrains of audiovisual expression in media networks: eclectic methods of video mash-up - Concretist experimentation in the $20^{\text {th }}$ century has been followed, in recent decades, with new expressions that explore the media's own cultural repertoires and the respective regimes of experience as materials of invention, enabled by audiovisual computing devices and by digital networks. As an empirical corpus, this article discusses the video mash-ups of the Eclectic Method, portraying them as pastiches of a concretist outlook that use sounds, images and discourses that are recurrent in the media culture and on the Internet. The philosophical concepts of "refrain" and "cutting" developed by G. Deleuze and F. Guattari (1997) will be revisited to discuss groove and cut'n'paste as methods used by "Vj mixtapes" to pick up and recompose "audio-logo-visual" materials from media networks. By injecting paradoxes in saturated experience, these "curator artists" promote experimentations in listening, visuality and imagination.

Keywords: audiovisual expressions; media networks; video mash-up; ritornello. 


\section{Introdução}

A prática do videomashup não é uma novidade em termos históricos, culturais ou estéticos. A esse respeito já se realizam inúmeros debates (incluindo documentários e reportagens) sobre direitos autorais, copyright, creative commons, pirataria, etc. ${ }^{1}$ No campo da filosofia da arte, problematiza-se a originalidade da criação, trazendo à baila a pertinência estética do pastiche, da paródia, da citação, da apropriação criativa na modernidade e na atualidade (dos quais os found footage são exemplares).

A história do pensamento da arte, por seu turno, busca detectar liames poéticos entre as colagens modernistas, a pop art e a bricolagem digital (cuja videoarte de Nam June Paik e os remixes de John Oswald ou Negativland são antecipatórios). Esse assunto também provoca, nos estudos culturalistas e da comunicação, especulações teóricas a respeito das condições contemporâneas da nossa experiência e das expressões criativas com o audiovisual em contextos midiáticos digitais.

Este artigo tentará, apoiado nos conceitos filosóficos de "ritornelo" e de "corte" reimaginados por Deleuze e Guattari (1997a), examinar os métodos e as ideias de experimentação dos videomashups, tendo como corpus empírico o trabalho do Eclectic Method. A discussão inicialmente aproxima afinidades nos modos de invenção do cinema experimental vertoviano e da música concreta nos anos 1940 e 1950, do groove e do cut'n'paste, nas últimas décadas, e, mais recentemente, do bootleg mashup ou bastard pop na internet.

Mais do que recensear essas experimentações na história da arte da colagem, do pastiche e dos ritmos concretos instaurados pelos modernistas, daí inferindo uma suposta linhagem de procedimentos inventivos que hoje reverberam nos videomashups, abordarse-ão tais estratégias de criação antes como um pretexto oportuno para se demonstrar que a potência da arte não se sustenta apenas nos seus materiais ou métodos. O repertório saturado das imagens, textos e sons no contexto midiático contemporâneo são realmente materiais priorizados pelos artistas do video mixtape, exortados pelos métodos do groove e do cut'n'paste. A singularidade de suas ideias encontram-se, contudo, na instauração de paradoxos que visam a desarmar hábitos de percepção, de memória e dos regimes estabilizados de sensibilidade e significações.

\section{O "ritornelo" e o "corte" como conceitos para se pensar a experimentação da arte}

O "ritornelo" se tornou, na história da cultura musical ocidental, uma estratégia que criava retenções mnemônicas e consequentes expectativas para a escuta. Era um recurso que operava por meio de reiterações métricas e melódicas memorizáveis, com durações

1 Cf. o documentário no qual também participa a então dupla Eclectic Method, Copyright Criminals (2010), dirigido por Benjamin Franzen, EUA. 
perceptíveis, que passaram a condicionar a composição cancional e musical no Ocidente. Esses estratagemas de passagem, retenção e desenvolvimento dos elementos sonoros vão criando um sentido formal intrínseco para escuta. Na música europeia dos últimos séculos, o ritornelo tornou-se um termo que passou a indicar modos de retornar à introdução, aos temas, refrões, às estrofes, seções ou a toda extensão de uma composição. ${ }^{2}$

O conceito de ritornelo reimaginado filosoficamente por Deleuze e Guattari (1997a) assumiu uma outra compreensão que redimensionou o termo tradicional. Para tanto, os autores diferenciaram três regimes ou modalidades para o ritornelo, todos, porém, inseparáveis entre si: o primeiro ritornelo, dos devires do Tempo; os ritornelos segundos, criados pela cultura humana; e os terceiros ritornelos, que se reinventam por meio da arte. $^{3}$ O primeiro supõe a autodiferenciação primordial do mover-se do Tempo, como uma perpétua transiência modulatória pela qual o mundo se recomeça continuamente e, por isso, recria-se sem parar. Os ritornelos primeiros são inexpressos e não têm forma ou substância, mas é pela sua perseverança duracional que tudo se expressa e se realiza materialmente. Esse modo do ritornelo seria justamente a força vibrátil do Tempo, imaterial, insistente, virtual, mas pela qual tudo se processa ritmicamente a ponto de se tornar material, atual (existente). É graças a esse misterioso movimento que tudo na realidade perdura, conserva-se e, paradoxalmente, renova-se e se recria, como um eterno recomeço de mundo. Esses ritornelos já existem a despeito de nós, já que preexistem à própria matéria, mas de seus ritmos somos naturalmente coparticipantes.

Os segundos ritornelos são especialmente humanos e se criaram como dispositivos para se domesticar o futuro, o acaso e o imprevisto, codificando o devir imponderável dos ritornelos primeiros em repetições padronizadas e controláveis. Os ritornelos da cultura são respostas da memória a infinitas modulações imperceptíveis e inconscientes que nos afetam. Esses recursos que utilizamos são uma espécie de retenção mnemônica para enfrentarmos a renovação contínua do mundo, que não cessa de bater à nossa porta.

No âmbito mais aproximado de nosso corpus empírico, podem ser mencionados o funcionamento previsível dos algoritmos e dos fluxos binários (como a própria binarização arquetípica do pensamento lógico), as repetições dos cálculos, a estabilização dos pixels, a regularidades das operações programadas, as frequências, os ciclos e as oscilações periódicas.

Afinal, tudo o que envolve as ciências, a matemática e a física que controlam a eletrônica e a informática também são ritornelos segundos. As fórmulas e aplicações nos planejamentos de marketing, gestão, métricas e heurísticas de usabilidade, processos

2 Todos esses recursos foram, nem sempre conscientemente, "subrritornelizados" por meio de ínfimas variações ao redor de um "eixo magnético" mnemônico, tais como as cadências de acordes em torno da tônica (daí o nome "sistema tonal"), as vibrações dos "harmônicos", que geram os timbres singulares de cada instrumento, entre muitos outros "microritornelos" subjacentes, implícitos, como o reconhecimento de elementos que remetem a certo gênero, a uma época, a um lugar (ritornelos da memória cultural).

3 O termo "Tempo" foi empregado pelos autores em letra maiúscula para diferenciá-lo da conotação meramente cronológica da palavra e aproximá-la de um conceito específico no vocabulário de seu pensamento filosófico: o Tempo como potência evenemencial, ontológica. 
de ações e reações detectadas codificadas pelos estudos administrativos da comunicação, realizadas pelas estratégias funcionais e de persuasão da publicidade (tais como os mecanismos de gratificações afetivas nos planos de conquista de adesão para o consumo) são igualmente segundos ritornelos. Sem esses ritornelos habituais talvez não estivéssemos sequer aptos à vida social. O ritornelo segundo é, portanto, um recurso fundamental pelo qual se conservam sensações e ideias que, sem essa síntese da memória, perder-se-iam para sempre.

O movimento fundador do ritornelo terceiro, presente na invenção da arte, arrebata-nos destes ritornelos do hábito e rasga os "véus semiósicos" que nos privam de sensações "virgens" do mundo. E a tarefa do artista é a de implodir as forças sedentárias dos ritornelos segundos. Parece que a arte nasce desses jogos de fazer e de desfazer ritornelos. Trata-se de deixar a experiência viver um pouco em durações familiares da memória, mas arrastando-a para fora dessas durações previsíveis e não mais convocada apenas a identificar ou reconhecer uma forma.

Daí emergem escapadas nem sempre previstas pelo gesto inicial. São ritmos que o artista insere nas cadências dos regimes de sentido e que podem descortinar o real em seu ritornelo primeiro, inovativo. O ritornelo da arte é um "retornar-para-o-devir", um retornar diferenciado e diferenciante.

Para conduzir a abordagem da questão que liga a experiência (ritornelos segundos) à experimentação (ritornelos terceiros), baseada no cut'n'paste, faz-se também necessário repensar o significado que Deleuze e Guattari (1997a) atribuíram ao conceito de "corte". A noção comum que se tem da palavra "corte" leva a imaginá-la, numa dada continuidade, como uma fissura, uma disjunção. Em termos tradicionais, toma-se o corte como uma figura negativa, como uma interrupção, um acidente, um ruído na comunicação, qualquer unidade fendida por uma incisão.

O corte não significa, porém, o contrário de continuidade, uma vez que a própria noção de "contínuo" começa por se definir justamente a partir de alguma ruptura. Foi Bergson (apud Deleuze, 2004) quem antecipou uma noção afirmativa (não negativa) à imagem conceitual de "corte". Segundo ele, qualquer movimento só passa a existir, para a nossa percepção, a partir dos cortes que a memória faz sobre a torrente das sensações. Toda continuidade só se define como um movimento, precisamente, por uma cisão das suas linhas anteriores, que já vinham carregadas de sentido e, por isso, estabilizadas como um regime mnemônico, linguístico, imaginário.

No trabalho da arte, o criador precisa inventar cortes para interferir nos escoamentos da existência condicionada pela cultura. A cesura é um gesto cindidor do artista que poderá desestabilizar o sentido prévio. No processo da criação, um corte traçado pelo artista fará cruzarem-se algumas durações do tempo cujas passagens não se notavam anteriormente. Cortar e colar podem ser pensados como modos de mostrar as durações diferentes que o tempo pode assumir. E o que faz o artista, de um corte a outro, é transformar o seu material (Deleuze e Guattari concebem como "material" toda matéria injetada de experiência humana). 


\section{O videomashup e o vjaying mixtape: experimentações audio-logo-visuais nas redes midiáticas}

Antes de lidar com o contágio entre circunstâncias criativas nos ambientes digitais ligados às redes midiáticas, vale aqui relembrarmos alguns experimentos de artistas face aos dispositivos técnicos audiovisuais no século XX, além de seus modos culturais e midiáticos específicos de circulação e experiência. Dziga Vertov (1896-1954) foi um desbravador na arte de cortar, colar e ritmar não apenas imagens, mas também trechos de gravações de gramofones, além de registrar ruídos naturais, urbanos ou maquínicos.

E, tal como criara o conceito de "cine-olho", ele expandiu essa concepção para o termo "rádio-ouvido": "se o cine-olho é a montagem do 'eu vejo', o rádio-ouvido é a montagem do 'eu ouço'" (VERTOV, 1922, p. 11). Todo artista moderno deveria, conforme defendia Vertov, concentrar as virtudes na tarefa de realizar uma arte do ritmo a partir de tempos "interimagéticos". ${ }^{4}$

No final dos anos 1940, compositores parisienses praticavam colagens eletroacústicas, nomeadas como musique concrète por seu pioneiro Pierre Schaeffer (1910-1995). Eles experimentaram possibilidades expressivas do magnetofone, extraindo e colando amostragens sonoras de todas as naturezas, captadas por microfones, justapostas, combinadas e editadas. O uso do toca-discos (a partir do sillon fermé, cujo som é gravado no acetato, com um sulco sem fim) e da fita magnética colada nas pontas criava ritornelos concretistas que permitiam adições e combinações posteriores de texturas sonoras heteróclitas. ${ }^{5}$

Nos anos 1960, uma alteração considerável logo ocorreu no universo criativo da chamada "música popular massiva", vinculada ao crescimento exponencial da indústria fonográfica. Entre procedimentos inspirados na música concreta e eletrônica, aparece o groove. Este termo (do inglês: ranhura, arranhão, entalhe) designa, em sua origem, uma prática anônima, um recurso utilizado por "não-músicos" que faziam a sua própria base musical (no caso, um trecho instrumental da música soul ou funk) para utilizá-la como playback e sobre ela cantarem suas letras.

Com o auxílio de uma lupa, talhavam no sulco do disco de vinil, no momento em que um chorus, uma estrofe, uma frase ou um compasso passariam para a parte seguinte. Isso faria com que a agulha retornasse para o início desse trecho previamente demarcado

4 Em seu Manifesto Kinoc (1922), Vertov enunciava que não seriam as imagens que interessariam ao olho do "artista kinoc" e sim as passagens, as transições, os intervalos entre as imagens ou, tal como ele as nomeava, as "interimagens".

5 Compositor reconhecido pelo experimentalismo antecipatório e pelas ideias provocativas, John Cage (19121992) também adotou a prática da colagem, do "ready-made sonoro" a partir da então incipiente tecnologia eletrônica da época no seu pensamento composicional. No campo do audiovisual, Norman Mclaren (1914-1987), cineasta e animador experimentalista buscou, por meio da composição heterogênea de imagens e de ritmos criados pela montagem, uma concreção cinematográfica que criava correspondências entre as modulações da escuta e da visão: os ritmos ópticos seriam criados a partir do ritmo sonoro, em contrapartida, novas sonoridades passariam a viver - pela transmutação da própria escuta - do movimento mesmo da imagem. 
como o ponto de entrada. O resultado gerava um ritornelo rítmico-sonoro. E assim, o toca-discos, um aparelho anteriormente restrito à reprodução musical, tornou-se um novo instrumento. A invenção do groove provocou um desdobramento que extrapolou vertiginosamente seu ato inaugural. Criar um groove passou a implicar o ato de destacar uma célula musical e tratá-la como ideia para uma nova sonoridade.

$\mathrm{Na}$ contemporaneidade, os argumentos críticos acerca da atual produção audiovisual denunciam, com alguma pertinência, a miscelânea, a mixórdia e a redundância discursiva onipresentes. Em contrapartida, as tecnologias digitais estimularam, ironicamente, a prática ancestral (e retomada por muitos modernistas) de reunir empiricamente materiais de naturezas heterogêneas e que vêm provocando outras disposições para a escuta, a visualidade e a imaginação.

O videomashup (ou videomixtape) se inscreve nessa prática disseminada pela internet na condição de um modo de expressão audiovisual que explora os próprios repertórios midiáticos e nossos regimes de experiência como materiais de invenção.

Elegemos aqui a emergência dos videomashups do Eclectic Method, originados no embalo do aparecimento dos bootleg mashups ou bastard pop. ${ }^{6}$ Formado em Londres, desde 2001, por Geoff Gamlen e Johnny Wilson, o projeto se dedica aos remixes audiovisuais. Inicialmente, exploravam-se apenas mesclas entre videoclipes e filmes. São exemplares a cena clássica protagonizada por Gene Kelly no musical Singing in the Rain (1952) mixada a um videoclipe de Iggy Pop; ou o clipe Hey Ya!, do Outkast (2003) com Paperback Writer, clipe dos Beatles (1966). O groove audiovisual de cunho concretista já se apresentava como a tônica desta fase criativa do Eclectic Method. ${ }^{7}$

No decorrer dos últimos anos, os materiais de criação empregados passaram a abarcar temáticas do repertório cultural midiático, imagético, discursivo, sonoro, cancional, musical, publicitário (clichês gestuais, cênicos e coloquiais do cinema, cacoetes e sestros de atores, performances típicas ao gênero dos musicais, conversações e narrativas, estereótipos da programação televisiva, do universo videográfico e do videoclipe, excertos de concertos de música, discursos políticos, imagens jornalísticas, hits virais da internet etc.).

Como, no entanto, problematizar, por uma orientação do pensamento que contribua para a apreensão teórica do trabalho do videomashup, pautando-se nos conceitos de "ritornelo" e de "corte" redefinidos por Deleuze e Guattari? Os parágrafos a seguir serão dedicados a tornar sensível - e quiçá inteligível - para o leitor tal estratégia de abordagem conceitual proposta pelos autores aqui priorizados.

6 O princípio de composição do bootleg mashup consiste em acoplar o playback de uma canção ao canto "a capela" de outra, conduzem a escuta a desestabilizar-se diante de uma frase melódica da voz que soa sob uma cadência harmônica diferente. Entre os projetos do gênero mais conhecidos pelo público figuram Osymyso, Go Home Productions e Hextatic.

7 As experimentações iniciais do Eclectic Method davam-se a partir do emprego de duas video turntable Pioneer DVJ-1000. 
Neste exercício descritivo sobre alguns trabalhos emblemáticos do Eclectic Method, tentar-se-á aproximar as imagens de pensamento dos resultados concretos alcançados pelas obras relatadas. Sugere-se uma consulta aos respectivos endereços eletrônicos nos quais os trabalhos em questão foram postados. ${ }^{8}$

Na peça Input output mixtape (16:59), por exemplo, frases e interjeições verbais recorrentes nos filmes são interpoladas entre si, sob um andamento rítmico que "anestesia" o significado linguístico e engrena o groove almejado, em que se instauram, entremeados, sonoridades, discurso e ritmos pictóricos. A palavra dream, falada ou cantada, sobrepõe-se por entre várias origens (uma canção folk; na fala do personagem protagonista de Orange Clockwork, de Stanley Kubrick, 1971; no discurso de Martin Luther King) e sofre interferências gráficas de desenhos de ondas senoidais, coexistindo simultaneamente com um timbre rascante, seguidos de imagens de programas televisivos dos anos $1960 \mathrm{e}$ 1970, intercalados em saltos temporais entre essas décadas.

A peça encontra seu primeiro groove ao articular quatro ou cinco fragmentos novamente cantados ou recitados da locução "dream", com sonoridades originais das fontes audiovisuais e arranjos instrumentais de outras fontes musicais (hip hop, sons invertidos, incisos melódicos sintéticos). A imagem sofre aqui alterações similares aos defeitos mecânicos e de interferência de ruídos de transmissão típicos da televisão analógica.

Cenas de entrevistas e de entertainers televisivos se entretecem; frases ditas se desarmam semioticamente e se costuram ritmicamente. Efeitos especiais de explosões cinematográficas pontuam os compassos de uma canção popularesca cantada num programa de televisão infanto-juvenil, seguidas de cenas coreografadas extraídas de filmes indianos à bollywood e um videoclipe de Beyoncé, em chroma-key e split-screen digitalizados, alternando-se com imagens de concertos do grupo Earth, Wind and Fire (com a qualidade videográfica dos anos 1970). De scratches audiovisuais migra-se para a palavra "down", pronunciada em entrevistas e letras de hip-hop, etc., sob a célula rítmica da soulmusic.

Em outro videomashup, 8Bit mixtape (2:44), mesclam-se as imagens de dois ou três games dos anos 1980, que depois se fundem ao Tetris, mas sob uma trilha eletrônica diversa, com sons de drum machine hightech. Segue-se uma trilha que remete às sonoridades da trance music, integrada a trechos de videogame Super Mario Bros, que sofre interferências de um excerto de hip hop, terminando com um som característico de "game over". 9

8 Cf. nas Referências Bibliográficas.

9 O imaginário cinematográfico e televisivo ligado à ficção científica é, por exemplo, apresentado em The Future (3:24) e Robots (2:47) cuja rearticulação musical dos sons do pequeno robô de Star Wars (1977) R2D2, é mesclada a fragmentos da canção Robots, do grupo Kraftwerk. Nota-se uma verve de humor nas escolhas, por exemplo, de interjeições de atores como as de Bill Murray, os sestros de Charlie Sheen, as frases-clichê de Arnold Schwarzenegger ou, por exemplo, a risada-clichê de Eddie Murphy. Para além de recortes de cenas clichês do cinema catástrofe, como em The Apocamix (2:16), há videoclipes de grupos do hip hop que se fundem a cenas de filmes de luta, ao estilo kung fu dos anos 1970 (como um mixtape só com cenas de Bruce Lee). Animações, como desenhos animados da Dysney, são igualmente exploradas. No vídeo Cultural Funking Overload (6:41), faz-se uma aproximação entre excertos de performances ao vivo de músicos do rock, do jazz, do soul, etc., cujas sonoridades, sob o groove, recriam uma composição audiovisual concretista. Há também vídeos metadiscursivos, que recortam frases em filmes e entrevistas cujo conteúdo trata de nossas próprias relações cotidianas com imagens, discursos e sons. 
Num outro exemplo, Snoop Lion Performance (3:23) começa sincronizando o vjay programando em "tempo real" um video mixtape, a partir de um Algoriddim Vjay da Apple, sob vários contextos gerados pelo chroma-key e em splitscreen diagonal com outros $d j$ 's em seus remixes e um videoclipe de Snop Lion com paisagens aéreas da Ilha de Manhattan. A câmera, agora subjetivada, visualiza a tela do software. Voltam as fusões entre imagens e sons em groove audiovisual do hip hop e do reggae, sobrepostos ou alternados à imagem do vjay protagonista. ${ }^{10}$

Outras peças jogam com cenas emblemáticas de filmes de diretores como Pedro Almodóvar, Tim Burton ou Quentin Tarantino. No trabalho The Tarantino Mixtape (7:16), raccords paralelos em splitscrenn de dispositivos em acionamento, com uma jukebox no filme Death's Proof; (2007) e um toca-fitas em Pulp Fiction (1994). Ainda em splitscreen, cenas de vários filmes que apresentam diálogos ao telefone.

A trilha sonora foi oportunamente construída sob o universo de canções dos anos 1960 e 1970 utilizadas nos diversos filmes do diretor. Cenas de combate e de luta corporal, como pastiches satíricos já recorrentes nos filmes de Tarantino, são postos em telas múltiplas que ora se emparelham, ora se interpenetram e realizam movimentos contrários, linearmente ou encolhem e se expandem dentro do espaço visual total. Os gestos de violência que se seguem são sincronizados com riffs de guitarra, em Kill Bill I (2003). Um breve beijo em close up assume, como transição, um groove que antecede a cenas "antológicas" em que as atrizes Mary Elizabeth Winstead (Death's Proof) e Uma Thurman dançam (Pulp Fiction), cujos planos são emparelhados sob a canção Lets stay together, interpretada por AI Green.

Novos excertos sobrevêm agora, simultaneamente, de cenas de diversos filmes do autor em que se usam drogas, sob uma colagem sonora concreta que culmina abruptamente com a retomada de fôlego da protagonista após receber a injeção de adrenalina e de recobrar os sentidos. Um novo groove surge sob a seleção de cenas em que porta-malas são abertos e filmados de seu interior, também como um sestro cinematográfico de Tarantino, que migra para os raccords e cenas em armas são manuseadas, com seu típico som mecânico, seguido dos sons de disparos, tornados ritmos concretos e entremeados com texturas da electronic dance music.

Madea Gets Remixed (2:04) é um pastiche de um filme musical sob um modelo insólito, gravado em palco, com a presença da plateia, Madea gets a Job (2013), escrito, dirigido e atuado por Tyler Perry. O videomix apresenta flashes da protagonista (Perry travestido da personagem Madea), sem trilha musical, até que ela diz: "you don't know me!" em duas situações diferentes da narrativa e, nesse momento, o ritmo da bateria se introduz. Os scratches audiovisuais se sobrepõem à batida, desacelerando o andamento

10 Atualmente o Eclectic Method divulga o Algoriddim Vjay iPad APP mixtape, um aplicativo da Apple para iPad por meio do qual se podem combinar duas pistas de áudio e duas de vídeo ao mesmo tempo. A despeito da sua tecnologia altamente "intuitiva", baseada na interface do touchscreen, há limitações de pré-produção e pós-produção, que se complementam com outros dispositivos (trilha sonora prévia, arquivos de imagens préeditadas, etc.) em suas criações. 
até sua voz se tornar grave como a de um barítono. Os grooves construídos a partir de certas frases pronunciadas nos seus diálogos se iniciam, ainda acompanhada apenas da drum machine. O groove passa a se compor de excertos de cenas diversas e novos timbres eletrônicos que remetem a brass band se inserem, sob uma melodia curta e reincidente.

Várias inflexões vocais consoantes aos contextos dramáticos dos discursos proferidos pela personagem são costuradas ritmicamente, o que faz atrofiar o sentido das sentenças verbais e enfatizando as sonoridades e a gestualidade teatral das cenas. Timbres sintéticos similares a sons espaciais de ficção científica se articulam aos grooves que se recompõem. A partir daí surge um novo groove mais heterogêneo: uma vocalização debochada da protagonista se acopla a um bofetão que ela desfere no personagem coadjuvante, numa cena diferente, com os respectivos ruídos realistas, novamente articulados a um fragmento de um grito de satisfação gestualizado num outro contexto. Surge uma palavra picotada pelo scratch e alterada em seu registro tonal, reiterando-se, porém, com elementos que vão se diversificando a cada retorno.

Novos timbres eletrônicos saturados movem o próximo groove, com interjeições, palmas, gestos e frases, fragmentadas e mescladas, do protagonista. Cenas em que a personagem sussurra são encadeadas, em seguida, gerando um novo "subgroove", sob uma trilha de fanfarra eletrônica, derivada do tema melódico inicial. O mixtape se encerra com uma frase isolada pronunciada pela protagonista, já sem nenhuma trilha musical.

No que tange à invenção musical como trilha sonora dos videomashups, a base musical é previamente criada por meio de sintetizadores vintage analógicos e de drum machines digitais. Talvez o imperativo das performances ao vivo tenha afetado as escolhas iniciais pelos gêneros da electronic dance music. O mérito experimental ligado às sonoridades emerge principalmente das texturas resultantes das sobreposições entre as faixas de áudio do material videográfico (diálogos, ruídos naturalistas, scores originais), inteligentemente exploradas como grooves que remetem aos estratagemas abertos pela citada música concreta francesa.

Algumas singularidades se notam nas texturas sonoras que se valem desde colagens de sons derivados da trilha original do material em jogo, até músicas, canções, diálogos, fonações, timbres eletrônicos, enfim, sonoridades e vocalidades do cotidiano midiático. Criam-se frequentemente ostinatos interessantes a partir de timbres pitorescos, tais como aqueles empregados em videogames.

\section{Considerações finais}

Para o horizonte conceitual de Deleuze e Guattari, todo artista se encontra, afinal, assomado de antemão por ritornelos segundos: percepções e lembranças, sentidos e sentimentos culturalmente estabilizados a povoarem o seu trabalho. Para os autores, essa seria a força inovadora da criação: o artista inventa ou reapresenta ritornelos paradoxais valendo-se dos ritornelos estabilizados da cultura, da linguagem e da comunicação. 
O videomashup, uma vez abordado a partir desse escopo, pauta-se no princípio de que o contexto cultural midiático seja o manancial de materiais prioritários como ritornelos segundos (valores, modelos, produtos, etc.) trespassados pelos ritornelos primeiros (ontológicos) e pelos ritornelos terceiros (sensações inventadas). O vjay de mixtape escolhe como materiais imagens, temas, discursos, rimas, escansões, os usos triviais de dispositivos técnicos, gestos, memórias, reminiscências, a língua e seus atos ilocutórios, o repertório midiático das canções, dos filmes, produtos televisivos e assim por diante.

Ao servir-se das produções midiáticas como materiais primordiais, o vj mashup pode fazer deles apenas estágios. Tal método demanda que ele se coloque em condição de embate com as forças sedentárias do sentido. É precisamente a partir das percepções sedimentadas que a experimentação com o videomashup produz a sua força inovadora. A sua estratégia criativa não propõe, portanto, um abandono literal dos hábitos de percepção já instalados. O impulso de invenção vai, imaginativamente, enxertando indeterminações no que já está sobredeterminado, inserindo distúrbios nas estruturas estáveis de sentido.

A tarefa de qualquer artista (que não se restringe aos ambientes digitalizados) é, por fim, a de tentar desestabilizar as tramas de redundâncias dominantes na linguagem e de desorganizar o regime de signos já estabelecido pela experiência. Trata-se de implodir algo no clichê (ritornelo segundo) e dele extrair alguma sensação singular.

Os videomashups pressupõem a des-narrativização do conteúdo original implícito nos materiais em prol da composição de ritmos plásticos-sonoros dos quais o pastiche emerge. Buscando, por assim dizer, des-conotar o material audiovisual de sua carga de estereótipos da cultura midiática (ritornelos segundos), é que a interferência (ritornelo terceiro) dos artistas de desktop poderá talvez restituir alguma novidade.

A captura e escolha dos trechos de música, áudio e imagens, posteriormente postas em grooves são orientadas pelo método de paradoxal adesão e desmontagem de conteúdos da cultura midiática. Pode-se, por fim, redefinir a natureza do groove no processo do videomashup como a de ritornelos audiovisuais receptivamente abertos ao acréscimo de intervenções, criando polirritmias plásticas, verbais e sonoras cuja indecidibilidade indefine o destino da memória, da escuta e do olhar.

A experiência, por algum tempo, desprende-se dos hábitos mnemônicos que estorvam seu contato com a novidade. A singularidade na sensação somente se fará na condição de se ativar o paradoxal nos regimes estanques da percepção e da significação. Apreende-se o videomashup como uma prática de montagem que não vive só de cortar e colar imagens, sons e vozes, mas principalmente de cindir os regimes habituais da experiência. O que se corta e se edita são, afinal, durações e não materiais ou formas. O artista interfere, pelos cortes, sobre as expectativas da memória. E o que a sua criação deve desarmar, a cada corte e a cada colagem, são os sentidos codificados e os regimes perceptivos. 
A montagem audiovisual, em vez de ser uma articulação de materiais (amostras de imagens, sons, falas, etc.), deve ser antes uma "mostragem" de durações e ritmos que afrontam o conforto de nossas percepções e cognições (ritornelos segundos). No videomashup, os cortes feitos sobre os materiais preexistentes, ao reinvesti-los de indeterminação (ritornelos terceiros), podem forçar a memória, a escuta, o olhar ou o pensamento a agirem diferentemente. Ao implodir os discursos com ritornelos terceiros, o artista instaura diferenciações ínfimas e oblíquas que podem desarmar os apoios recognitivos da memória e dos regimes triviais da experiência perceptiva (ritornelos segundos). Desse "desamparo semiósico" é que renasce o novo, que se revirgina o futuro-do-devir (ritornelos primeiros), desinibido das balizas criadas pelos códigos e hábitos da lembrança.

O trabalho criativo em circunstâncias em que predominam o excesso informacional e a fadiga das sensações - contexto particular do videomashup- pressupõe encontrar um caminho por entre tantos ritornelos redundantes e torná-los materiais prenhes para a invenção. O vj de desktop transpõe para seu trabalho as relações com a realidade virtual saturada e instaura algum paradoxo nos enunciados já estabilizados.

São esses artistas da internet que se liberam das restrições normativas das narrativas do audiovisual e se convertem em frequentadores inventivos da rede. Eles parecem comungar entre si a compulsão de agirem como uma espécie de curadores, de colecionadores, de antologistas, de espectadores singulares que promovem experimentações criativas com os discursos imagéticos, sonoros e textuais midiáticos. Os artistas do audiovisual na internet ainda se contagiam pelas ideias dos pioneiros do pastiche, do ready-made, da arte concreta, do cut'n'paste, que também se interessaram pelas potencialidades do impensável e do indizível, do silêncio e do invisível.

Rodrigo Fonseca e Rodrigues é pós-doutorando em Ciências da Linguagem na Universidade Nova de Lisboa. É doutor em comunicação e semiótica pela PUC-SP. É editor da revista Mediação e autor do livro Música eletrônica: a textura da máquina.

rfonseca@fumec.br

\section{Referências}

DEATH'S Proof (2007). Direção: Quentin Tarantino, EUA.

DELEUZE, G. Bergsonismo. Rio de Janeiro: Ed. 34, 2004.

DELEUZE, G.; GATTARI, F. O que é a filosofia? São Paulo: Ed. 34, 1997a.

DELEUZE, G.; GATTARI, F. O Ritornelo. Mil Platôs n. 4. São Paulo: Ed. 34, 1997b. 
ECLECTIC METHOD - A Brief History of Sampling. Disponível em: <http://vimeo.com/ eclecticmethod>. Acesso em:

ECLECTIC METHOD - Booty Bounce. Disponível em: $<$ http://www.youtube.com/watch?v=uUSdDpma6s\&feature $=c 4-$ overview-vl\&list=PLs71 eNbvavNtutPklwQc_T5bKuFXaAktU>. Acesso em: 11 de agosto de 2013.

ECLECTIC METHOD - Madea Gets Remixed. Disponível em: <https://www.youtube.com/ watch?v=GyKNYykoPaQ $>$. Acesso em: 14 de agosto de 2013.

ECLECTIC METHOD - Takes It In The APP. Disponível em: <http://www.youtube.com/ watch? $=$ MMyw3B_vVHs $>$. Acesso em: 24 de maio de 2013.

ECLECTIC METHOD PRESENTS: Snoop Lion Performance vjay Mix. Disponível em: <http://www.youtube.

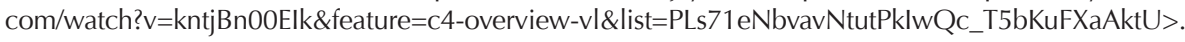
Acesso em: 21 de julho de 2013.

KILL Bill Vol. I (2003). Direção: Quentin Tarantino, EUA.

MACHADO, A. Pré-cinemas e pós-cinemas. Campinas: Papirus, 1995.

MADEA Gets a Job (2013). Direção: Tyler Perry, EUA.

ORANGE Clockwork (1971). Direção: Stanley Kubrick, EUA.

PULP Fiction (1994). Direção: Quentin Tarantino, EUA.

SINGING in the Rain (1952). Direção: Gene Kelly e Stanley Donen, EUA.

STAR Wars (1977). Direção: George Lucas, EUA.

VERTOV, D. Rèsolution Du Conseil dês Trois Du 10 avril 1923, Articles, Journaux, Projets. Paris: Cahiers Du Cinéma, 1972.

Artigo recebido em julho e aprovado em setembro de 2013. 